\title{
Emergent Questions for Orientation and Transitional Professionals
}

\author{
Michael T. Miller, Editor
}

As noted in this edition of The Journal of College Orientation and Transition, transition can be interpreted broadly to encompass faculty, staff, student, and even alumni transitions. The Campus Notes section of the journal, for instance, provides us with two areas of transition that we as an academic community have not explored in great detail: the transition of students out of college and the orientation and transition of new faculty to their host campuses. I believe that an emerging area for orientation professionals will be to combine their expertise with other areas on campus, for instance, applying orientation strategies to offices of human resources and faculty development. As a community of practitioners, this means that we need to collectively take stock of where we are, document what we do, and find a way to meaningfully evaluate what we do.

Of the three articles included here, one of the more interesting, broader topics is whether faculty can, should, or are involved in various aspects of student affairs. Pope raises the question of whether or not divisions of student affairs should claim a stake in determining what programs are offered, how they are implemented, etc. His article is a good first step in opening this dialogue further, and needs to be explored more directly in relation to student orientation. Similarly, the Bai article on student retention at a nontraditional university has bearing on the entire orientation community, and could be well replicated substituting transitional programming experience (satisfaction?) with retention and academic achievement. I think that kind of hard data has the potential to increase the profession's value in the eyes of key decision-makers.

The orientation course article illustrates the ability of introductory university orientation courses to be adapted to different settings, in this case, a graduate school setting. Comparative research examining how programs like these work in graduate and professional schools could help the academic community understand better the causes and rationale for attrition in post-baccalaureate education, contributing to the definition of whether attrition is intentional.

Emergent themes identifiable from these topics include: what are the cycles or stages of the transitional mindset, and are these similar or different from the other transitions that are experienced on campus (faculty, staff, students to alumni), and if they are similar, what does that mean? The notion of retention work is continuous, and it would be interesting to explore retention in the setting of orientation, that is, identifying participation at various times during a program, and what factors mitigate matriculation

Michael T. Miller, Ed.D., is Associate Dean of the College of Education at San Jose State University, and Editor of The Journal of College Orientation and Transition. mmiller5@email.sjsu.edu 
in the transitional program. I also noticed here the broadening of the idea of orientation to expand beyond new, first-time college student orientation, and an appreciation for different types of programs and institutions, such as the non-traditional student-centered institution in Bai's study.

From my perspective as an associate dean and the editor of this journal, I have seen an emerging trend of senior student affairs administrators either coming from faculty ranks or reporting directly to a provost or similar vice president for academic affairs. If this line of thinking is indeed accurate, then it will be interesting to notice how college presidents are selected in the future, and what transitions senior student affairs administrators are capable of making. Although I have no evidence of this, I seem to have noticed more senior student affairs administrators assuming college president positions, and I would imagine that in part this transition has been made possible by the high stature of senior student affairs officers on campus. If this high stature is somehow diminished, does that in turn lead to fewer growth opportunities for the senior student affairs administrator?

The response to issue one of the Journal has been quite good, and I am hopeful that the orientation community will continue to work with the Journal's editorial board to share research, ideas, and perspectives on our profession. I look forward to working with many of you during the next several months in preparation for volume nine, and I am available to provide whatever assistance I can. 